\title{
Configuring the digital city of Amsterdam
}

\section{Social learning in experimentation}

\author{
M.J. VAN LIESHOUT \\ TNO Institute of Strategy, Technology and Policy, \\ Delft
}

\begin{abstract}
Design and dispersion of new socio-technological configurations are studied by many varying sorts of scientific disciplines, ranging from communication studies to technology studies. In this article, the configuration and appropriation of new socio-technical constituencies are studied and subsequently interpreted in terms of a rather novel concept: social learning. On top of what is known about appropriation and configuration processes, social learning adds another point of view, elaborated from a perspective known as the social shaping of technology. It takes Beck and Giddens' reflexive modernization as starting point, and uses this to elaborate social learning into two dominant modes: the mode of experimentation and the mode of control. The Digital City of Amsterdam is used as exemplar to demonstrate configuration and appropriation processes and how these can be interpreted as elements of the mode of experimentation.
\end{abstract}

\section{Key words}

digital cities - experimentation as mode of learning • introduction of new media $\bullet$ social construction of technology $\bullet$ social learning 


\section{INTRODUCTION}

The explosion of electronic networks and the growing number of citizens with access to these networks have led to a steady stream of publications about the phenomenon of 'virtual communities'. These communities can be of various kinds, ranging from social movements dispersed over the world, to inhabitants of a city. Various authors have attempted to categorize the many different forms of appearance of digital communities and cities (Dutton et al., 1987; Graham and Aurigi, 1997; Graham and Marvin, 1996; Komito, 1998; Van Dijk, 1997). Graham and Aurigi differentiate between 'grounded' and 'non-grounded' forms of digital cities, in which the grounded forms refer to 'real cities' that have a digital counterpart in cyberspace, while the non-grounded forms connect people from geographically dispersed locations (Graham and Aurigi, 1997: 36). Graham and Marvin (1996) concentrate on the dispersion of boundaries of real cities, due to increasing importance of telecommunication infrastructures; yet another approach comes from Van Dijk (1997) who uses different dimensions to discern between public and private initiatives, and between possible modes of communication (one-to-one, one-to-many, etc.). These varying approaches show that the social innovations that may be related to these electronic networks are manifold and fit many different frameworks of understanding. They feed ideological expectations and discourses about the contribution of digital cities to reviving democracy and closing the gap between politics and citizens (Mosco, 1990, 1996; Schalken et al., 1996). Within Europe these approaches are boiled down in one of the Bangemann challenges in which digital cities are seen as one of the ways 'to improve the quality of life of the European citizens, increase the efficiency of our economic and social organization and reinforce its cohesion' (Bangemann, 1994: 6).

Within the context of the European research project, Social Learning in Multimedia (SLIM), ${ }^{1}$ I have studied the rise of an electronic community of a specific kind: the digital city of Amsterdam (known as DDS: De Digitale Stad [The Digital City]). Having over 100,000 citizens only five years after its inception, and being an often quoted example of a successful digital city, DDS has reached a kind of professional status that is seldom obtained within electronic communities. In line with the objectives of the SLIM-project (understanding factors that contribute to success and failure in developments that surround the introduction and uptake of multimedia in various social settings), I have analysed DDS as an example of a dynamic and on-going configuration of technologies and people. The analysis is done in terms of appropriation and configuration strategies, and in terms of a relatively new concept: social learning. I start with an interpretation of the development of DDS in terms of configuration and appropriation strategies. Then I introduce the concept 'social learning' and demonstrate the usability of DDS 
as almost ideal-typical exemplar of one of the dominant modes of social learning: the mode of experimentation.

\section{AN EMERGING DIGITAL CITY: BRINGING CULTURE AND TECHNOLOGY TOGETHER}

DDS - the Digital City of Amsterdam - was the result of close cooperation between two social groups that both felt the need to explore the social opportunities of electronic networks. Amsterdam-based people with a media and culture background who were working at the politico-cultural centre 'De Balie', took the lead in association with members of the Dutch hackers' organization, Hacktic, in order to start a social experiment with new digital media. The roots of the DDS experiment can be traced back to the early 1990s, when people interested in media started to experiment with new media. ${ }^{2}$ Local and national elections to come in early 1994 formed a legitimate background for the experiment. The idea of creating a digital environment in order to experiment with new social forms was decisively influenced by the American-based Freenets. Unlike Freenets, the digital environment to be constructed was intended to enable all forms of social communication without restriction. To attract as many people as possible, the metaphor of the city was consciously used, with citizens, i.e. tourists, as subscribed users, i.e. visitors. Interestingly enough, this metaphor of the city has never led to installing democratic bodies, such as a city council, and to providing democratic rights for the 'citizens'. Within a few months, a textual interface was constructed, working groups were formed, subsidies were received, and co-operation of the municipal authorities was obtained. From the first day of its launch, the experiment was very successful in terms of media exposure. The experiment - which was originally planned to last for only 10 weeks starting on 15 January 1994 - was covered by all major broadcasting companies, and it had extensive coverage in newspapers and magazines. It was the first time that news about the internet shifted from the economic to the cultural pages of newspapers or programmes on TV. Within the first few weeks of the start of the experiment, it was clear that the experiment should be continued. It attracted many thousands of visitors, the modems in Amsterdam were all sold out, the modem bank to connect to the digital city had to be doubled within a few weeks (from 12 to 20 lines); the experiment was, in short, the talk of the town. In an optimistic mood, the initiators asked for more and longer lasting financial support, but were confronted with a negative decision from the public authorities. They received funding for the remainder of that year, but were at the same time required to produce a business plan that would make them self-supporting within the following year. Meanwhile, the hackers' organization, Hacktic, had decided to become a professional internet access provider, which left the experimenters with new media on their own. Now, with hindsight, we 
may conclude that the formula they came up with, which is now basic to DDS, turned out to be a golden one. DDS was one of the few organizations with hands-on experience of organizing electronic media (debating groups, the organization of cyberspace). This gave DDS a 'unique selling point', that was exploited in establishing commercial activities. With the profits from its private activities DDS was able to continue the provision of the electronic public domain. Pivotal between public domain and private enterprise was the role DDS gave to knowledge creation and dissemination about new technologies (data-mining, real audio and real video, 3Dmodelling, etc.) and new organizational models in cyberspace (how to integrate broadcasting and the internet; how to combine synchronous and asynchronous media, etc.). From public initiative DDS turned into a private foundation that was intent on maximizing the synergetic effects of its experiences in both the public and the private domain, thus ensuring a firm basis for future survival. In this article we focus on the public activities of DDS. ${ }^{3}$

\section{THE DESIGN AND DISPERSION OF NEW MEDIA}

DDS can be seen as the creation of an electronic environment that enables a virtual community to be established. The electronic environment is shaped by a mix of technological, social, cultural, economical, juridical, political and organizational processes. Designers and users are related to each other by way of a set of technological tools and constraints, social rules and habits, expectations and cultural patterns about uses, non-uses and misuses.

Designers try to develop an environment that matches their image about prospective users best, and shape a socio-technical environment in which social and technological aspects are intimately related to each other and define and redefine each other. Within media studies this modelling of the designer-user interaction is well known and extensively studied. ${ }^{4}$ Considering technology to be socially constructed implies a breach with classical innovation studies which consider technological artefacts to be a unifying whole to be dispersed as they are into a community of users. Many researchers have hinted at the shortcomings of a model that presupposes such a linear relationship between the construction of an artefact and its presentation to and uptake by its users (Dosi, 1982; Nelson and Winter, 1977; Rogers, 1983). In the field of information and communication technologies, these observations are all too valid. Usually, ICT-products are still malleable and adaptable to specific forms of use. Only with hindsight, the technical and the social characteristics seem to be neatly separated. Identifying the usability of a device means attempting to stabilize the significance of a specific socio-technical setting. Introducing a new artefact or a new tool means that the (perceived) user will have to accommodate the artefact or tool into his or her life. Translated to domestic settings, a process 
of domestication (Aune, 1996), and of taming the artefacts (Miller, 1987) occurs. In this article, we concentrate on two sides of this accommodation process: configuration and appropriation strategies.

\subsection{Configuring the user}

In a well-known essay Steve Woolgar describes how the construction of a PC involves the configuration of the user (Woolgar, 1991). Woolgar describes this process as a conflict between the designers of the PC and the people outside the social circles of the designers. He underscores the fact that the design process is a straightforward attempt to define the boundaries in which 'the' device and 'the' user meet each other and match-up with each other. According to Woolgar, it is the user who is configured, not to say disciplined, by the specific design of a particular PC. Woolgar presents an interesting paradox. In speaking about the user, it seems as if no user at all is identified. It is the ideal-typical format of the user that is configured by the system, not any specific user with any specific characteristics. What counts is whether the device works, irrespective of the user who wants the device to work for him or her. The dilemma for the designer is obvious: making a customized and personalized design implies a myriad of possible design strategies and solutions; making only one design implies losing sight of the user. According to Woolgar it is the last strategy that is typically at work. Designers attempt to incorporate 'the' user in the device.

One way of incorporating the user is by using metaphors. Especially in ambiguous and complicated contexts, metaphors may serve as 'guiding principles'. Schön identifies two distinct meanings of a metaphor: one which relates to anomalies in language, and another which perceives metaphors as perspectives on the world in which a product ('a perspective, or frame, a way of looking at things') and a process ('by which these new perspectives on the world come into existence') can be discerned (Schön, 1993: 147). Schön hints at interpretations of a metaphor that are well known in the world of new media, like 'information superhighway' and the 'digital city'. These metaphors configure perceptions and uses and have high value as rhetoric devices as well. In configuring DDS, the metaphor of the city played an important role, as can be derived from the following reconstruction.

Configuring DDS The objectives of DDS have remained the same over the years: increasing people's participation in the electronic public domain, contributing to knowledge development and transfer, and contributing to economic development. ${ }^{5}$ The technical infrastructure of DDS has changed radically since its inception. In less than a year and a half, three interfaces were introduced. Subsequent versions of the interface that formed the virtual environment of the city were labelled DDS1.0, DDS2.0 and 
- Table 1 Characteristics of the three interfaces of DDS

\begin{tabular}{|c|c|c|c|}
\hline & DDS 1.0 & DDS 2.0 & DDS 3.0 \\
\hline Introduction date & 15 January 1994 & 15 October 1994 & 10 June 1995 \\
\hline Interface & Freeport/gopher & Lynx/Mosaic & WWW \\
\hline Text/graphics based interface & $\begin{array}{l}\text { text-based user } \\
\text { interface (UI) }\end{array}$ & $\begin{array}{l}\text { text based UI/ } \\
\text { graphical UI }\end{array}$ & $\begin{array}{l}\text { graphical UI/ } \\
\text { text based UI }\end{array}$ \\
\hline Structure of the interface & menu oriented & $\begin{array}{l}\text { cursor oriented/ } \\
\text { hyperlinks }\end{array}$ & hyperlinks \\
\hline
\end{tabular}

DDS3.0. These interfaces were crucial in communicating a specific image of the digital city. They were enframed by the technological opportunities that existed 'in these days'. In Table 1 an overview is presented of the technical requirements of the three subsequent interfaces that DDS has known so far.

DDS 1.0 The first interface took only a few months to design. The idea of DDS was taken from the US-based Freenets and so was part of the software. The Freeport software was adapted to the local situation in Amsterdam and, where needed, extended with Gopher (using a cursor to move through a list). The metaphor of the city was reflected in the organization of the interface: it had a post office, where email could be gathered and sent; a public forum that encompassed the different moderated discussion groups; a town hall; an election centre (because of the prime target of DDS: the elections of April 1994); a central station that formed the gateway to the internet; a house for arts and culture (reflecting the media background of the initiators); a square to meet other visitors, etc. (see Figure 1). The first interface configured its users as being visitors to a digital city. The interface itself was a boundary device: it constructed the virtual boundaries of a city. It did this in a strict sense: when leaving the city by connecting to a place outside the city, the Freeport interface was replaced by another Unix communication standard (like Telnet). ${ }^{6}$

DDS 2.0 When the world wide web as a standard was introduced, DDS was among the first organizations within the Netherlands to implement it. ${ }^{8}$ DDS2.0 clearly was a technology-driven approach. The designers wanted to have an interface that enabled experimenting with the newly introduced graphical interfaces. The web enabled artists to use the new medium to experiment with new media forms, with new designs. Unfortunately, the introduction of an interface based on the web meant a step backwards with respect to communication facilities: entering a pub or a discussion group meant leaving the web interface and starting a Telnet session. Some of the early citizens protestedagainst this sign of 'technological progress'. They saw the new interface as an impoverishment of the communicating facilities that were fundamental to the objectives of the digital city. DDS2.0 essentially 
De Digitale Stad

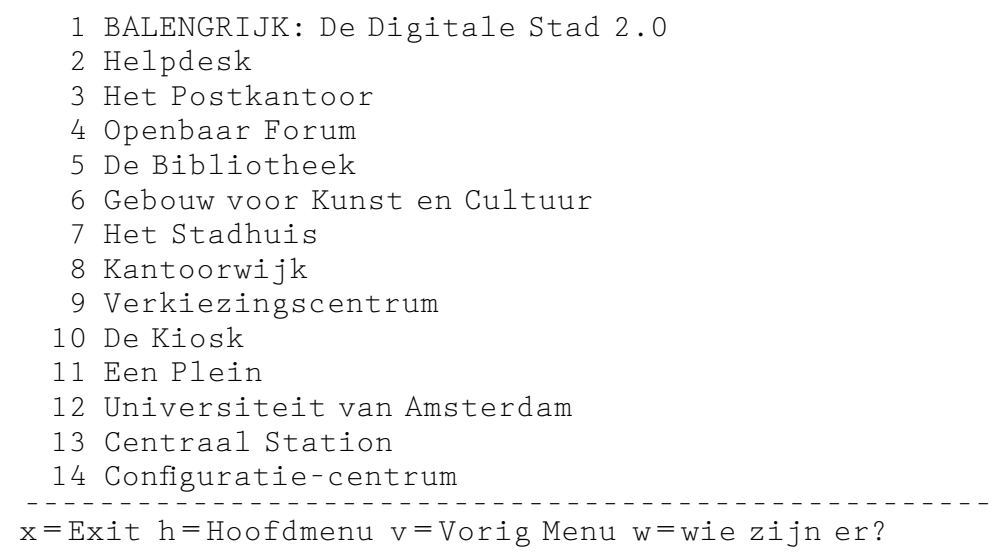

Keuze ? :

- Figure 1 The textual interface of DDS1.0 and DDS2.0

Note: As the attentive reader may notice, in the figure it is indicated that this is the entrance gate to DDS2.0. As a matter of fact, the lay out of DDS1.0 was similar to this interface. The software of DDS1.0 was however, Freeport software, while the software for the textual interface of DDS2.0 (of which this is the picture) was Lynx.

was a text interface with graphics (see Figure 2). The old Freeport-based textual interface was replaced by a new textual interface that was based on Lynx. Lynx used the cursor to indicate items and to follow hyperlinks. This caused troubles in the beginning, since 'natural' uses of the cursor did not always work. ${ }^{9}$ For the designers, DDS2.0 did not include a change of perspective on the user: 'the' user remained an abstract person. The designers were aware of the impoverished communicating facilities. Their choice was, however, supported by the staff of DDS who saw the need to experiment with new technologies in order to keep momentum in the innovating activities of DDS. So, the loss of functionality in communicating tools was taken as inevitable. This did not mean that communication was considered to be less important than information. It was just the limitations posed by technology that structured the functionality of DDS.

DDS 3.0 Work on DDS3.0 started immediately after the launch of DDS2.0. Since a survey among the citizens of the digital city had shown that most citizen were male youngsters, it was decided that DDS3.0 should be useful and interesting for as many people as possible. ${ }^{10}$ Of course, this was rhetoric. DDS1.0 was, in line with the vision of the initiators, also meant for all who wanted access. The 'Access for All' principle was, however, never turned 


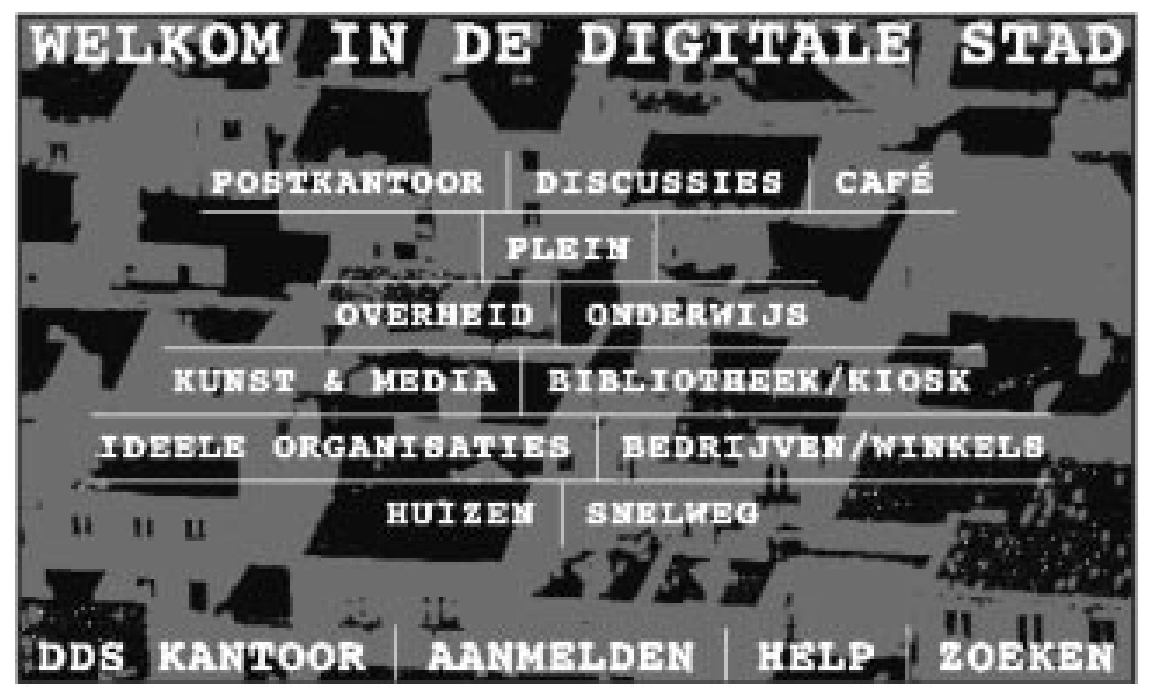

- Figure 2 The graphical interface of DDS2.0

into practice. A second principle was that the city should be accessible by both high-end and low-end computers. This implied that a text-based version should remain available. Third, there should be different ways to gather information within the city. Just as in a real city, it should be possible to get lost, and to discover unknown spots by chance. Fourth, both novices and advanced users should have fun in visiting the city. Interestingly enough, this led to the introduction of a 'power-tool' for the so-called 'power-users': a kind of shell structure that enabled those who were familiar with the UNIX-based structure of the shell to get what they wanted in a fast way. In designing a navigation structure, several models were tried: an old city centre with canals, a matrix city like New York, a village street model and even a model of a planetary system. Eventually a model with squares was chosen since this allowed for flexibility in providing information content while it fitted the metaphor of a city quite well (see Figure 3). The citizens of DDS3.0 kept the privileges they already had in DDS2.0, in having an email address and having the privilege to enter pubs. The privilege of making a personal home page was added. To make the city more like a real one, citizens were allowed to use fantasy identities wherever they presented themselves. It was however always possible to trace the real identity of a person, by a simple and fast procedure. The city should, after all, be a lively place. As is stated in the official documents: 'We don't want a dull - clean - city that requires political correctness of anybody.' ${ }^{11}$ Not all the new features in DDS3.0 worked as was intended. The textual interface, for instance, was constructed by literally translating the graphical information into texts. This was a bad design choice. It led to indications in 


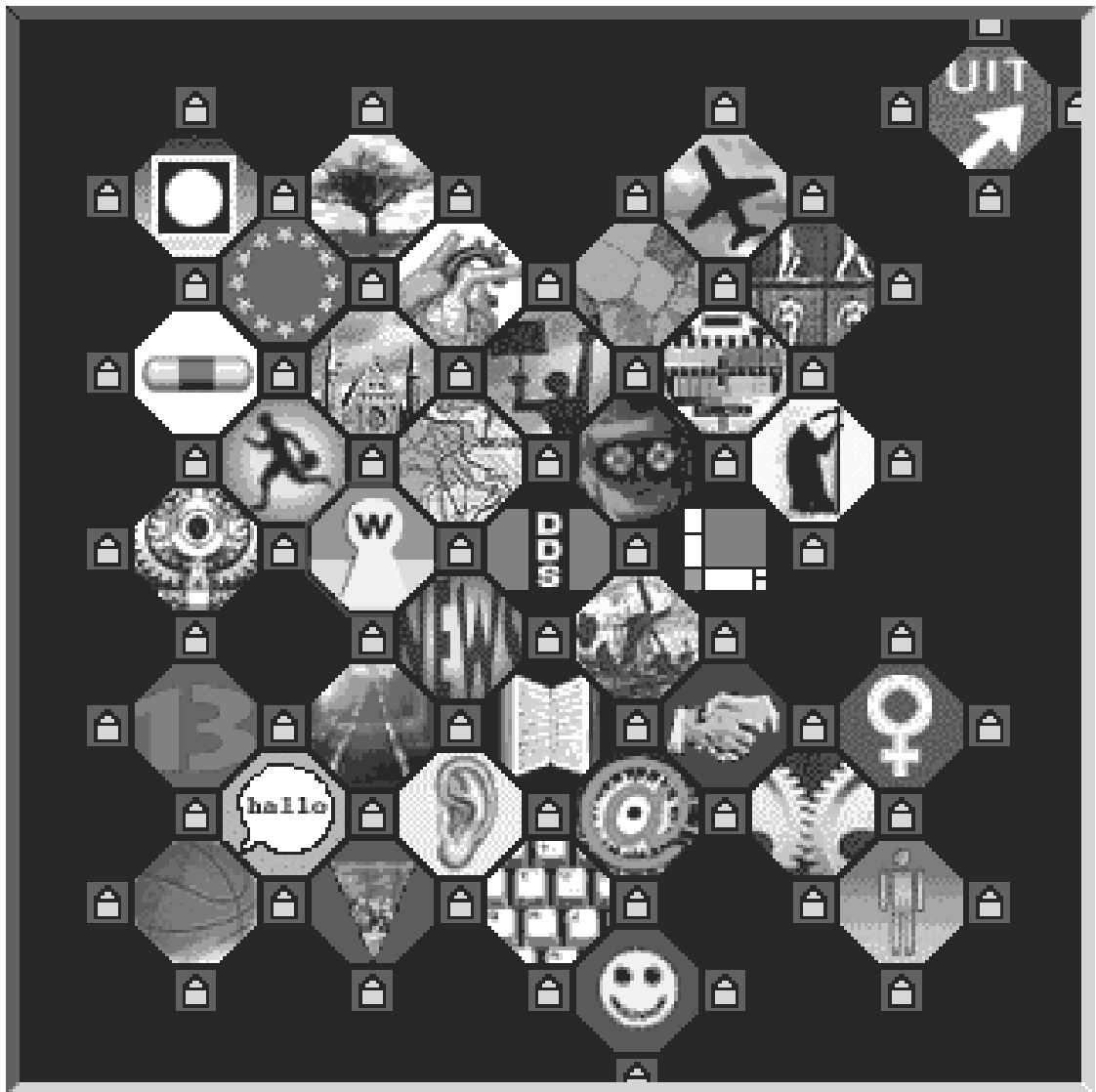

- Figure 3 The square structure of DDS3.0 (houses are located in between the squares)

the textual interface like: 'Go north'. Another problem remained the dynamics of the city itself: how to indicate something new, how to introduce a new square, or a new house at a square? And finally, how to introduce a new interface? DDS3.0 was based on a conscious reflection about the representation of information, communication and the user. Though user requirements were formulated, these requirements were never operationalized. They remained formulations on an ideological level, and never reached the status of technological incentives. The ideology enforced general accessibility to all users, male or female, old or young, highly or poorly educated, rich or poor. What this meant in terms of design strategies was never solved. By instructing groups of a particular type (like older women who were new to computer use) problems popped up that were very basic to using a computer, such as how to use a mouse. ${ }^{12}$ The designers did not like the idea of designing for such an undifferentiated group, but neither did they try to reduce this lack of differentiation. ${ }^{13}$ The user was, 
again, configured as an abstract entity. The design led to asynchronous modes of communication, which required deliberate action on the part of the users to achieve meaningful communication. ${ }^{14}$ The designers succeeded in giving the city a 'face'. Unfortunately, this face was and is a rather static one. Though over time more squares were added to the digital city, the overall 'look' of the city has not changed since its inception, in June 1995. This is a design problem that is more and more felt to be serious. ${ }^{15}$ A city must grow, must change, must be dynamic.

Configuring the city and the citizens To understand what the designers had in mind when constructing a digital city, looking at the subsequent versions of the interfaces (in combination with the results of the interviews and the written material on the construction process) enables the reconstruction of the mental models used by the designers. In the construction of the first two interfaces of DDS, the user was configured by means of the metaphor of the city. The metaphor had both ornamenting and ordering functions (cf. Van Twist, 1995: 47), and introduced a specific perspective on the world (cf. Schön, 1993: 147). The designers were aware of the fact that the users could not be treated as a homogeneous group, but they were reluctant to differentiate between specific groups. In the design of the interface yet to come, there is a discussion of DDS4.0, the use of 'scripts' that may be applied by citizens themselves. ${ }^{16}$ The designers are seen to be aware of the 'designer's dilemma' without being able to offer satisfying solutions. The metaphor of the city enables cyberspace to be configured in a conscious and understandable way. Not only the technical artefact (the interface itself) but also users are configured (enrolled) in scripts as being a 'citizen', 'owning' a house, visiting a pub, etc. However, these scripts do not represent all crucial aspects of life as experienced outside the digital city. Despite being a citizen, influence on the government of the city is very limited for the user, and the parallel between a house owner in real life and one within the city is limited to the possession of real vis-à-vis virtual space. These limitations did not prevent the growth of the city, showing the strength of a metaphor.

But the configuration process entailed more than just the use of metaphors and scripts. The configuration process began with the attempt to use the political elections to start an experiment with a hitherto rather unknown medium, for the sake of the experimentation itself, and for the sake of studying its potential for countervailing power within a subculture. The configuration process also covers the (hierarchical) structure of the city, which - notwithstanding its democratizing appeal - also had a tight topdown structure. This apparent contradiction is particularly interesting since even the identification of this contradiction did not lead to serious attempts to introduce more democratic procedures into the city apart from some 
'give-away' public forum in which citizens also had a voice (cf. Francissen and Brants, 1998: 34). The organizing strength of the new medium, bringing together over 100,000 citizens within four years, apparently did not empower the citizens themselves to join forces for a more democratic organization of the city. As we will see, other forms of countervailing power on a more 'local' scale show that democracy can be organized within the city, though it circles around concrete issues more than around an abstract appeal of a concept. The structure of the city was however not turned into a solid structure, but remained open, flexible and adaptable. The flexibility worked two ways: it left space for citizens and citizen groups to organize their own affairs, and it gave the designers opportunities to join the public and private parts of the city. The golden formula of using the public part of the city as a permanent experimentation space in which new technical gadgets could be tried in a user group of several tens of thousands, while using the private part of the city to generate revenues that enabled the continuation of the public sphere that DDS represented, is an important element of the configuration process of DDS. The public part of DDS was oriented in change, in experimentation for the sake of experimentation. It did not matter what actually happened in the city, as long as the city showed that it was in a situation of permanent change - just like a real city. This experimental attitude, shared by both the cultural community and the hackers' community that started the project, is another important aspect of the configuration processes that formed the city.

\subsection{Appropriating the artefact}

What is configured, has to be appropriated by the user. This correlation between the two concepts should not be understood as if both concepts relate to distinct groups of actors with different activities. Particularly in the field of new media, the role of the user as co-designer gains importance. Designers, in their turn, have to appropriate what is offered (for instance, design tools) and have to incorporate the expected behaviour of the user in the design. The result of the appropriation procedure is that a tool, or a functionality, is integrated in the views, habits and daily practices of the user.

Akrich uses the concept 'script' to analyse how objects are appropriated (Akrich, 1992: 207-9). She suggests that designers inscribe specific norms and values in the artefact or practice (for instance that one has to be a skilled user of text processing programmes, or that one is a novice in surfing the internet); appropriating the practice or artefact means matching with these norms and values. Rommes et al. (forthcoming) use the concept of scripts to analyse the implicit and explicit gendering of technical artefacts and socio-technical constellations. DDS is one of the socio-technical 
constellations they study. They argue that gendered scripts prevent appropriation by excluded (i.e. female) user groups.

\section{A popular image - citizens of the digital city Appropriation processes} are complicated processes. They encompass a variety of actions simultaneously and can seldom be reduced to only one or two factors that determine the shape of the appropriation process. In the case of DDS, appropriation processes have different forms, given the many faces the city offers to both its inhabitants and people merely passing by. In the following sections, I start by presenting demographic figures about the city, and complement these with a few illustrative examples of specific appropriation processes.

Demographic appropriation During the period leading up to 1998, three surveys were held to get information about the background of DDS citizens. The first one was held during the first experimental period (Schalken and Tops, 1994), the second was held two years later $(1996)^{17}$ and the third was held in $1998 .{ }^{18}$ The surveys did not deliver representative results as they were not based on a random sample of citizens. Still, the overall impression is that they provide valuable information about the backgrounds and activities of the DDS population. The number of citizens has grown over the first four years from 13,000 in May 1994 to 45,000 in May 1996, leading to over 100,000 citizens by the beginning of 1999. DDS

- Table 2 Demographic figures of DDS citizens

\begin{tabular}{lccc}
\hline & $\mathbf{1 9 9 4} \mathbf{( \% )}$ & $\mathbf{1 9 9 6}(\mathbf{\%})$ & $\mathbf{1 9 9 8} \mathbf{( \% )}$ \\
\hline Sexes & 91 & 84 & 79 \\
Male & 9 & 16 & 21 \\
Female & & & \\
Age & 58 & 71 & 74 \\
Younger than 30 years & 3.5 & 3.5 & 3.5 \\
Older than 50 years & & & \\
Education & 72 & 76 & 20 \\
University/higher education & 23 & 20 & 18 \\
Higher secondary education & 4 & 4 & 22 \\
Lower education & & & 1 \\
Geographical origin & 45 & 22 & 40 \\
Amsterdam & 1.3 & 0.5 & 48 \\
Abroad & & & 12 \\
Activities & 61 & 39 & \\
Work & 31 & 56 & \\
Student & 8 & 5 & \\
Others & & & \\
\hline
\end{tabular}

Sources: Schalken and Tops, 1994; Beckers, 1996, 1998 
- Table 3 Characteristics of use

\begin{tabular}{lcll}
\hline Contact With OTHER CITIZENS & $\mathbf{1 9 9 4}(\mathbf{\%})$ & $\mathbf{1 9 9 6} \mathbf{( \% )}$ & $\mathbf{1 9 9 8} \mathbf{( \% )}$ \\
\hline Very often & 4 & 19 & 19 \\
Regular & 17 & 37 & 29 \\
Sometimes & 33 & 23 & 28 \\
Never & 46 & 21 & 24 \\
\hline
\end{tabular}

Sources: Schalken and Tops, 1994; Beckers, 1996, 1998

does not escape a stereotypical composition of its citizens, though the number of new females is higher than the national average. It is interesting to note that only a minority of citizens (i.e. inscribed users) comes from the city of Amsterdam, thus underscoring the virtual character of the city. Half of the citizens belong to the student population. Internet and email are the most important reasons to subscribe to the city. Communication within DDS (by pubs and discussion groups) is less appreciated, though it is interesting to note that with the shifting constitution, half of the growing population claims to have digital meetings on at least a regular base (see Table 3). While interests in the original incentives of DDS (creating a virtual community around a number of societal themes) has diminished (according to the initiators), interest in communication per se has grown. Interest in information provided focuses mainly on computer technology ('how to make your own homepage') while arts, culture and politics score significantly less. The most popular square is still the 'central square' (with all kind of information about DDS itself), followed by computer-related squares. ${ }^{19}$ Men use bookmarks significantly more often than women, who use search functions more often. Women spend more time in the city, while men more often use the city as a starting point for surfing the world wide web. Notwithstanding its socio-cultural background, the population of DDS does not escape being stereotypically composed of young higher educated men. The city attracts more male than female users, and more students than workers. We do not know whether the group of passers-by (tourists) is differently composed. There is however not much ground to suggest that the tourist group will deviate from an average internet user group.

Squatting in cyberspace DDS started as an illustrative example, aimed at showing new and possible uses of new media, and experimenting with these new media. It was a social experiment itself. It retained this character throughout its existence. It has always been an objective of DDS to provide for a playing field for citizens, tourists, staff members, ideological and commercial organizations. This playing field has been used creatively, as the following illustration shows.

DDS3.0 introduced the opportunity to have a house in the city. Of today's 100,000 inhabitants some 1300 own a house. Each citizen can create a house, when space is available. Once space became scarce, and the houses 
were all occupied, both citizens and the staff of the city introduced solutions to this problem. Both solutions have been implemented. A usual practice is that once a home is owned, within a relatively short period of time the home is embellished, with graphics, with personal information, with interesting links, or whatever. Sometimes, however, no visible changes are made for many months. In line with the ideology of the squatting movement - a social movement that had its heydays in the late 1970s and the early 1980s in the Netherlands - DDS introduced a squatting law. It was permitted to squat a house that had not been changed in the last three months. This was indicated by the 'local authorities' by placing a nail on the door. Everybody could put a claim on a house with a nail by placing his or her mark on it. The citizens introduced another solution. Within the space available (500 KB for each house) they introduced the possibility to share more houses behind one door. They came up with the principle of a flat. A flat consists of a number of houses. All houses share the same front-door. A flat may consist of a number of houses that relate to a common background, or it may consist of a number of houses (and house-owners) that do not share anything in common except for the front-door. Some flats have created an elevator that combines the different 'floors' in the flat. Others have introduced stairs. Each house within a flat has a limited amount of disk space. There will always be a 'house master' who is the original houseowner. Both approaches show how metaphors of the real life are transplanted to the virtual life and enable solutions to problems with the socio-technical organization of the city. Both solutions introduce their own dynamics. In case of the flats, for instance, communication between the inhabitants is organized by distributing a digital newspaper, that tries to highlight problems that inhabitants of a flat might share. In the case of a squatted house, civilian procedures are established that enable an inhabitant to fight the squatting indication. (A squatting indication is when the authorities put a notice on the door indicating that squatting is permitted.)

The city as attractor Notwithstanding the changing population (which, according to one interviewee, ${ }^{20}$ exchanged its original composition of close bystanders for one of relative outsiders), appropriation by communication has gained importance over the years. This may have led to sub-populations within DDS and to functions of DDS not known by the DDS officials. According to one member of the design team of DDS3.0, he was 'lured' into the city, even though he initially did not consider DDS to offer a very interesting digital platform. But somehow the city started to 'live a little ... the influence of thousands of inhabitants became stronger and stronger' and it became difficult to withstand the urge to visit the city, and to see what happened. ${ }^{21}$ Another form of end-user appropriation is the creation of the 'Underground', a subculture within DDS with its own rules. Anyone can 
visit the Underground, but only a few consider themselves to be part of the Underground movement. ${ }^{22}$

Appropriating the city Appropriation is basically an individually guided process: individual people (citizens in case of DDS) will have to appropriate a tool, artefact or idea, which means that eventually the tool, artefact or idea has to be integrated into the cultural context of the individual. The extent to which this integration occurs, and the manner in which it occurs determines the 'mode' of appropriation. ${ }^{23}$ In the case of DDS we can perceive different manifestations of appropriation processes: first, the inscription as a citizen, which is a very important aspect of the appropriation process; second, the appropriation of the city as metaphor, as demonstrated by the use of 'squatting laws' and the elaboration of this in rather different forms, showing flexibility in the 'modes' of appropriation. The changing patterns over time, as demonstrated in the changing demographic composition of the citizens, shows another aspect of flexibility in appropriation processes: while the early generations of citizens may have felt some kind of interest in the more ideological backgrounds of DDS, the latter generations (i.e. after the first year of the existence of DDS) did not bother about this ideological orientation, but proved to be vivid users of the communicative opportunities offered by the city. The existence of the Underground, and the organization of the pubs are yet other manifestations of the heterogeneous manner in which the city can be appropriated: many different trajectories of appropriation can be discerned that co-exist and probably influence each other in specific ways.

\section{SOCIAL LEARNING IN NEW MEDIA}

The analysis presented in section three on the configuration and appropriation strategies that can be demonstrated in the case of DDS, can easily be transferred into an analysis within a framework known as the social shaping of technology (Bijker, 1995; Bijker and Law, 1992; MacKenzy and Wajcman, 1985). This framework concentrates on understanding the process of socio-technical change in which social and technical aspects cannot be separated, but dialectically shape and reshape each other. Historical accounts of technological developments usually pay limited attention to the wider social milieu surrounding the development of a technological configuration and usually neglect the mutual influence of social and technological factors. ${ }^{24}$ The framework of the social construction of technology is based on cultural and sociological theorizing: it starts from the assumption that actors will attribute specific meanings to specific developments and that these meanings reflect specific circumstances. An artefact or technological configuration does not have a prescribed meaning the very moment it is 'released' from the laboratory. Its meaning is negotiated by interested parties, 
which are always able to re-negotiate their findings when they think this to be appropriate. ${ }^{25}$ Methodologically, the social shaping approach requires any explanation about a socio-technical configuration to be unbiased with regard to success or failure. The analysis should instead be aimed at understanding why a specific practice is labelled to be successful, while another practice is thought to have failed. Success and failure have to be explained instead of taken for granted. In a similar vein, the indication of 'good' and 'bad' practices must be analysed on what constitutes good or bad practices. Do we understand why specific guidelines contribute to 'good practices'; do we, as a matter of fact, understand what precisely is understood by 'good practices'? Both aspects (success and failure, good and bad practices) require an unbiased and symmetrical approach. By offering thick descriptions of the cases under study and by searching for regularities, the list of methodological requirements is completed. ${ }^{26}$

Technology studies (to which the social construction theories belong) and media studies thus share a common perspective on technological artefacts and on how these artefacts or configurations are configured, i.e. appropriated. Social shaping, however, remains a rather descriptive approach. In order to come to a more prescriptive or normative position, some authors have coined the concept of social learning to indicate how acquired insights by researchers might attribute to a learning of society in how to address the emergent socio-technical practices best. According to Rip et al. (1995) efforts in constructive technology assessment (CTA) have provided researchers with new insights into improving the social uptake of new technologies. Within CTA, the mutual shaping of social context and technology is under close supervision of stakeholders who adjust the shaping process 'on the spot'. Social learning then refers to the dissemination of the aggregated knowledge and insights in the shaping process. They hope this may advance the more successful processes and diminishes the failures. Jaeger et al. (forthcoming) take a similar position in presuming that social learning includes processes of negotiation and alignment of views, thus reducing friction and as a consequence optimizing the societal uptake of new developments. Experiments, trials and projects that are aimed at testing technological and social objectives, function as locus of social learning. Social learning is opposed to technical learning by presupposing that any trial or project needs to be addressed as a process of combined social and technical change. Brian Wynne (1995) takes the concept of social learning one step further. He refers to late modern sociologists such as Beck and Giddens who perceive profound changes in the organization of (western) society, due to the intrinsic reflexive nature of social practices. Wynne identifies a 'reflexive version of social learning' that 'would involve the systematic exposure, investigation and debate of implicit social models and assumptions that structure "factual" analyses of technologies, impacts and 
risks' (Wynne, 1995: 31). Wynne thus emphasizes the importance of a discourse on presuppositions regarding the relationship between technology and society. This might contribute to a better understanding of how to deal with new technologies in a social context.

\subsection{Mode of experimentation vis-à-vis mode of control}

The reflexivity Beck and Giddens point at has, however, features that enable a different kind of proactive analysis of socio-technical practices than Wynne's elaboration presumes. Beck and Giddens refer to the fact that almost all processes of societal change are reflected by society itself. This may be reflection, just as a mirror reflects an incoming array of light. The array of light is bounced back, and may cause interference with other arrays. This kind of reflection is basic to Beck's analysis of the risk society, in which he points at the consequences of activities of society that may severely interact with future prospects of society (for example, in the case of caused environmental degradation) (Beck, 1992). The reflection can also be consciously monitored and surveyed, with the results of this monitoring or surveillance somehow fed back into the process of change itself. Giddens refers to the disembedding and embedding mechanisms that are basic to how modernity affects society (Giddens, 1990; 15-16). The spread of expert knowledge all over society increases the availability of resources to be used in redirecting the processes of change, for better or for worse. The process of change over time has been addressed as a specific form of learning of society, a learning that is not necessarily related to a change in the psychological or mental state of mind, but that in first instance refers to the process of change itself (Sorensen, 1996). Society thus learns, where learning is embedded in the change process itself. The learning may go unnoticed, but it also may be consciously evoked and used.

Within the SLIM project we have tried to differentiate between the instances of social learning that can be discerned in distinct societal practices. For this, we used our experience with DDS to introduce two dominant and juxtaposed modes of social learning: the mode of experimentation vis-à-vis the mode of control. DDS has chosen an approach in which the setting is considered to be an open social shaping process, i.e. in which no a priori objectives have to be reached, in which no strict ending of the experiment is foreseen, in which there is a minimum on rules and restrictions to what may happen within the boundaries of the digital city. This mode of social learning emphasizes the flexibility in design, the adaptability of both users and uses, and the explorative setting that is maintained all over the life cycle of the project (that has no perceived ending). That is why we label this mode the experimental/flexible/adaptable mode of social learning. Opposed to this mode, one finds the regulation/ control mode, that presupposes central regulation of the developmental 
process by the designers, a clear separation between designers of new media and the users, a perspective on the added value of the project that is developed by the designers, and a deadline or finite life cycle for the entire project. ${ }^{27}$ Many projects in which new uses of new media are explored, follow the logic of the regulation/control model. They have a strict ending, they have formulated objectives, they have evaluation and feedback procedures on pre-set times, and they are meant to deliver information that enables the creation of a 'product' (which may be of different kinds, from a smartcard for a public transport system to an information system in which citizens can consult public authorities). In contrast, DDS is an open-ended experiment, in which awareness of the process of change, is continuously fed back from the private domain to the public domain and vice versa.

Both modes give rise to different learning processes. It is wrong to suggest that, in general, one mode leads to better results than the other. Much depends on the specifics of the situation. As far as the societal diffusion of new media is concerned, the case of DDS shows that an experimental approach can be valuable, not only as part of a start-up, but also when a project has matured and has entered a solidification phase. This conclusion is an interesting one, and should at least lead to reconsidering the predominant approach in most trials and experiments that are undertaken today with new media. Though it is usually admitted that the initial phase should be open ended, after some time it is expected that control will take over again. DDS offers an argument for keeping space for experiments, acknowledging that contemporary processes of change require continuous uptake of new technological devices, reconstructing new gadgets, aligning new user groups, developing new user contexts, etc.

DDS also fulfils the more implicit notion of social learning, as point of aggregation and dissemination of information and knowledge about its whereabouts. It is a web-based city, which can be visited by all connected to the internet. It communicates and disseminates information and knowledge about its existence, its experiments, its uses, without knowing to whom and to what extent. It contributes to awareness about the uses, misuses and non-uses of new media, which is easily communicated by means of the internet and other electronic networks. Though the presence and use of electronic networks is not the only mode of disseminating information, it seems fair to suggest that it at least feeds the reflexive processes as mentioned by Beck, Giddens and Lash (cf. Giddens, 1990; Beck, 1992, Beck et al., 1994).

\subsection{Configuration and appropriation strategies as social learning}

Social learning adds another layer to theories on the social construction of new media. While the analysis of configuration and appropriation processes 
enables the identification of processes of change over time, related to specific groups of actors (i.e.. designers and users), social learning enables the identification of strategies used consciously or unconsciously to evoke configuration and appropriation processes. When a socio-technical configuration resembles the mode of control best, processes of appropriation and configuration will most probably be consciously monitored and surveyed, while the results will be fed back into the process of change in order to re-direct the process of change on pre-set objectives or targets. Being in line with the mode of experimentation, the appropriation and configuration processes may or may not be monitored, while possible results do not necessarily have to be fed back into the process of change. It is our claim that many experiments and trials with new media follow the logic of the mode of control, thereby constraining the development of the sociotechnical configurations and probably neglecting opportunities to experiment with an unpredictably innovative potential of these projects. ${ }^{28}$

Within DDS, analysis of the configuration and appropriation processes as presented in the preceding section, give rise to labelling DDS as an almost prototypical form of the mode of experimentation. Though the inscription procedure - users being inscribed as 'citizens' of the city - seems to correlate better with the mode of control than with the mode of experimentation, this is only a minor part of the configuration/ appropriation process. Being a citizen enables various uses of the facilities the city offers, running from building a house to visiting pubs and to participating in newsgroups. The innovative uses of available facilities, for example, the creation of the Underground as a shielded domain within the city, or the construction of flats to increase the number of potential home owners in the city, demonstrate the open-endedness of the city and the flexibility of configuration as well as appropriation processes at work in the city. We also mentioned the attempt of the designers to create a virtual space that should be open to everybody and that should mimic the vivacity of a real city. The Digital City is an on-going experiment, in which the malleability, adaptability and flexibility of the new ICT, the new media in relation to the uses that can be made of it, is taken as basic ingredient. Since the variety of choices and the continuing input of new uses and new gadgets lead to a principally open space that lacks an a priori structure, any representation of the Digital City is a temporary representation that is constrained in (virtual) space and in time. The experimentation space has not led to strict regulations and constraints in using the digital city. ${ }^{29}$ This continuous (re-configuration process is a typical but underestimated aspect of modern practices around new media.

With respect to appropriation we have already argued that DDS seems to offer an incentive strong enough to attract and thus modify behaviour of citizens. It is important to emphasize that this process of appropriation 
cannot be a static one, as if it is a matter of mastering the tool and its uses. New media such as DDS are in permanent flux, leading to a continuous process of change, to new facilities, to new ways of 'being in the world'. Once a user becomes enrolled in the city, it depends on his or her involvement whether the original appropriation continues over time. The precise flux of the population (newcomers, leavers and duration of being inscribed) is required to give a first answer on this interesting aspect. Whether citizens appropriate the city or not, is not a prime concern to the designers of the city. This is an interesting feature that adds up to DDS being prototypical for the mode of experimentation. It is up to the citizens (the inscribed) themselves to continue their subscription to the city. If they are no longer interested in being a citizen, and they do not visit the city for a period of three months, they are automatically removed from the subscription list. No attempts to keep them as valuable 'human resources' are undertaken. Even when the appropriation process has led to the final stages of appropriation as identified by Silverstone et al. (1991), there remains a free choice to end the subscription to being a citizen without anybody paying much attention to this step. The city remains open, even after having gone through a number of initiating procedures.

\subsection{Successful or failed experiences within social learning}

A final interesting issue to be dealt with is whether DDS, being an oft-cited example of a successful digital city, is really successful. Today, the Netherlands is host to over 100 digital cities and regions. DDS has been an exemplar for many of these initiatives, at least as way of organizing the electronic public domain. ${ }^{30}$ None of these initiatives however, have reached the same kind of professional organization as DDS. They reflect the diversity of digital cities as presented in the introduction of this article. The fact that there is no successor to DDS that even comes close to it (in terms of number of citizens, organization of the digital environment, professional staff and commercial activities) is interesting in itself. It shows the transferability of 'good practices' to be highly problematic. It also shows that what should be counted as successful practices and what should not, are not easily defined. To start with the first, 'good practices' are usually defined as good practices since they enable imitation in different settings. DDS gives rise to many aspects that might be imitated: the metaphor of the city; the interfaces that represent a specific layout of the city; the 'golden formula' of the mix of private and pubic affairs with technological innovation in between; the open character of the public city as experimentation space. Except for DMA (Digital Metropol Antwerp), that presents itself explicitly as being a successor to DDS, no digital cities are known to have imitated the concept 
of DDS. The absence of more than just one successor to DDS feeds the idea that transferability of innovative results from an experimental project is usually highly problematic. Acquired knowledge reflects the local characteristics of where it stems from; appropriation and configuration strategies are difficult to generalize. Though it is always possible to lift some of the experiences in a given situation to another situation, imitating the totality of the experience is almost impossible. Theoretically, an experimental situation cannot be judged on the extent to which it lives up to its expectations, since these expectations will not be very precisely formulated. This also seems to be the case in DDS. Though analysing the emergence of DDS gives rise to many interesting insights - and even has been basic to the identification of the mode of experimentation - DDS also reflects the problems of identifying success.

\section{CONCLUDING REMARKS}

Within the field of technology dynamics, new media are studied as sociotechnical phenomena. The Digital City of Amsterdam (DDS) functions as an exemplar of the introduction and subsequent evolution of such new media. In this article the construction of DDS has been studied from the perspective of the designer and the user. Analysing configuration and appropriation strategies contribute to a better understanding about the dynamics of DDS. The social shaping of technology emphasizes the interpretative flexibility regarding notions of success and failure, and good and bad practices. DDS offered an interesting test-case for studying this flexibility. The more descriptive approach of social shaping was complemented with an analysis of social learning processes that DDS revealed. These were to be found on two levels. The first level indicates that DDS is a prototypical example of the mode of experimentation, in which no strict objectives or deadlines are formulated, in which a discourse between designers and users is encouraged and in which private and public interests are served in common. As such, DDS gives rise to social learning by experimentation. The second level relates to the manner in which DDS contributes to an overall awareness of contemporary processes of change, related to new media. Taking DDS seriously, it might be interesting to enforce more open experimental settings as 'normal' approaches of embedding new media. ${ }^{31}$

\section{Acknowledgements}

The author would like to thank Ruud van Dael for his constructive comments on earlier versions of this article, and (in alphabetical order) Michael van Eeden, Joost Flint, Steven Lenos, Nina Meilof, Marjolein Ruijg and Marleen Sticker for their willingness to be interviewed. 


\section{Notes}

1 SLIM was one of the projects of the EU Targeted Socio-Economic Research programme, situated in the Fourth Framework programme. Eight universities contributed to SLIM: Bremen, Copenhagen, Dublin, Edinburgh, Lausanne, Maastricht, Namur and Trondheim.

2 See Van Lieshout, 1999 for a more detailed description of the historical origins of DDS.

3 As of January 2000, the business structure of DDS has changed profoundly, leading to separating the public and private services of the digital city foundation. This change is related to the changing socio-economic environment in which DDS operates, especially the rise of free internet service providers. In this article I do not take these latter changes into account. They are not influential on the argumentation I want to put forward.

4 See SLIM final report for a presentation from the various perspectives on this modelling (Williams et al., 2000).

5 www.dds.nl/dds/info/alginfo2.shtml\#doel (18 March 1999).

6 Unix formed the kernel of the system. All application software (like the Freeport software) made use of Unix and its command structure.

7 As the attentive reader may notice, in the figure it is indicated that this is the entrance gate to DDS2.0. As a matter of fact, the layout of DDS1.0 was similar to this interface. The software of DDS1.0 was however, Freeport software, while the software for the textual interface of DDS2.0 (of which this is the picture) was Lynx.

8 The Dutch public broadcasting company VPRO was the first organization to establish a www site; DDS was second.

9 In a DDS document the most prominent differences are explained. 'No, you don't move to the right with a right hand arrow, but you follow a link. The right hand arrow has the same functionality as pressing Enter. And the left hand arrow does not move you to the left, but takes you back to the former link. If you want to go to the left, you will go up. Sometimes it happens that in a phrase two options are highlighted. Intuitively many people try to go from the first option to the second by using the right hand arrow. You will unlearn this habit in due time, but it might be cumbersome at first.' (http://www.dds.nl/dds/info/soft.html) (18 March 1999).

10 www.dds.nl/ robvdh/Projekt (18 March 1999).

11 www.dds.nl/dds/info/regels.html (18 March 1999).

12 The Dutch prime minister, Wim Kok (aged 59 years), recently showed in a television programme that computer illiteracy runs through all demographic sectors. When using a mouse, he aimed it at the computer screen, as if it was a remote control.

13 Interview Marjolein Ruijg and Michael van Eeden (17 November 1997). The design team for DDS3.0 comprised three people: Marjolein Ruijg, Michael van Eeden and Rob van der Haar. They focused on the design of the interface in the public domain, though they had activities in the commercial domain of DDS as well.

14 To give one example of this asynchronous mode of communication: using the digital pubs that are available in DDS requires an electronic form to be filled in, which is subsequently sent to a stack, from which it can be downloaded by all other visitors to this pub. All forms in the stack are chronologically presented on the computer screen of the visitors. This leads to asynchronous communication, and has the effect that all threads of conversations are interwoven with each other. All things said in a given timeframe (for instance the last two minutes) in the virtual pub are stored, and 
subsequently released in time order to all present. All responses are also stored and subsequently released.

15 Interview Marjolein Ruijg and Michael van Eeden (17 November 1997).

16 Interview Joost Flint (6 January 1998).

17 www.swi.psy.uva.nl/usr/beckers/publicaties.html (18 March 1999)

18 www.swi.psy.uva.nl/usr/beckers/publicaties.html (18 March 1999)

19 This is congruent with another observation I made in comparing different cities. The digital city of Delft publishes a weekly list of most popular pages. It turned out that, after the central page of the city, the five most popular pages were dedicated to a computer-related issue: how to make your own html-document!

20 Interview Nina Meilof (17 November 1997)

21 http://www.dds.nl/ robvdh/Projekt/

22 Interview Marleen Stikker (13 January 1998)

23 Silverstone et al. (1991) have developed a typology that conceptualizes the various stages of appropriation up until the moment in which the tool, or artefact or idea is incorporated into the daily practice and its meaning is conversed into the sociocultural repertoire of the individual. In terms of the social shaping of technology we speak about the interpretative flexibility surrounding the meaning of the artefact, and the processes of closure that lead to a more or less stabilized interpretation (cf. Bijker, 1995).

24 These were mainly economic-oriented innovation studies that considered technological artefacts to be commodities that could be exchanged on the market. Historical accounts did not usually pay much attention to broader social influences, and focused on successes more than on symmetrical descriptions.

25 An interesting elaboration of this approach is presented by Feenberg in his analysis of the Télétel case (Feenberg, 1995).

26 For the sake of completeness, we have to add that these methodological rules are basic to the social construction of technology. Other theoretical frameworks, especially those that belong to the actor network theories, have slightly different requirements, due to a slightly different perspective on the role of human and nonhuman (i.e. technological) actors. See Latour, 1988 for a detailed and very readable presentation of actor network theories.

27 This typology is formulated both by Van Lieshout et al. (in press) and Van Bastelaer and Lobet-Maris (1999) as a result of the SLIM research. Van Bastelaer and LobetMaris formulate a third model of social learning that they label the 'laissez faire model'. According to Van Bastelaer and Lobet-Maris, the 'laissez faire' model corresponds most to the internet culture. Their formulation of the 'laissez faire' model comes close to the mode of experimentation as we use it.

28 I have to emphasize that there is no way to predict possible uses in different circumstances, leading to a claim that can only be substantiated by researching many different cases on similar variables. Within the SLIM-project this has been done in situations concerning the public sector, education and the cultural industries, leading to the creation of the conceptual framework as presented in this article.

29 An interesting example of a rule is the fact that citizens are not allowed to offer pornographic material on their homepages. The reason for this rule is not the fact that the initiators are opposed to pornography, but that 'All those visitors that take a look at these pictures, increase the cost of (IP-)traffic, and slow down the servers, which decreases the acceptability of other houses.' (http://www.dds.nl/dds/info/regels.html) (21 March 1999). 
30 The Department of Economic Affairs commissioned DDS in 1994 to write a handbook on how to create a digital city. In early 1995, the handbook was presented at a conference organized by the Department of Economic Affairs. I do not know what the impact of this handbook on the construction of other digital cities has been (Schalken and Flint, 1995).

31 Normal in a Kuhnian sense, as contrasted to a period of transition from one, scientific, perspective to another (Kuhn, 1970).

\section{References}

Akrich, M. (1992) 'The De-scription of Technical Objects', in W. Bijker and J. Law (eds) Shaping Technology/Building Society: Studies in Sociotechnical Change, pp. 205-24. Cambridge, MA: MIT Press.

Aune, M. (1996) 'The Computer in Everyday Life: Patterns of Domestication of a New Technology', in M. Lie and K.H. Sorensen (eds) Making Technology Our Own? Domesticating Technology into Everyday Life, pp. 91-120. Oslo: Scandinavian University Press.

Bangemann, M. et al. (1994) 'Europe and the Global Information Society: Recommendations to the European Council', CD-84-94-290-EN-C, Brussels, 26 May.

Beck, U. (1992) Risk Society: Towards a New Modernity. London: Sage.

Beck, U., A. Giddens and S. Lash (1994) Reflexive Modernization: Politics, Tradition and Aesthetics in the Modern Social Order. Cambridge: Polity Press.

Beckers, D. (1996) 'Rapportage onderzoek bij de Digitale Stad 1996', URL (consulted 21 March 1999): http://www.swi.psy.uva.nl/usr/beckers/dds96/verslag/

Beckers, D. (1998) 'Rapportage onderzoek bij de Digitale Stad 1998', URL (consulted 21 March 1999): http://www.swi.psy.uva.nl/usr/beckers/dds98/verslag/

Bijker, W.E. (1995) Of Bicycles, Bakelites, and Bulbs: Towards a Theory of Socio-technical Change. Cambridge, MA: MIT Press.

Bijker, W.E. and J. Law (eds) (1992) Shaping Technology/Building Society: Studies in Sociotechnical Change. Cambridge, MA: MIT Press.

Dosi G. (1982) 'Technological Paradigms and Technological Trajectories', Research Policy 6: 147-62.

Dutton, W.H., J.G. Blumler and K.L. Kramer (eds) (1987) Wired Cities: Shaping the Future of Communications. New York: G.K. Hall.

Feenberg, A. (1995) 'Subversive Rationalisation: Technology, Power and Democracy', in A. Feenberg and A. Hannay (eds) Technology and the Politics of Knowledge, pp. 3-22. Bloomington and Indianapolis: Indiana University Press.

Francissen, L. and K. Brants (1998) 'Virtually Going Places: Square-hopping in Amsterdam's Digital City', in Tambini D. Tsaragousianou and C. Bryan (eds) Cyberdemocracy - Technology, Cities and Civic Networks, pp. 18-40. London: Routledge.

Giddens, A. (1990) Consequences of Modernity. Cambridge: Polity Press.

Graham, S. and A. Aurigi (1997) 'Virtual Cities, Social Polarization and the Crisis in Urban Public Space', Journal of Urban Technology 4(1): 19-52.

Graham, S. and S. Marvin (1996) Telecommunications and the City: Electronic Spaces, Urban Places. London and New York: Routledge.

Jaeger, B., R. Slack and R. Williams (forthcoming) 'Europe Experiments with Multimedia: An Overview of Social Experiments and Trials', The Information Society.

Komito, I. (1998) 'The Net as a Foraging Society', The Information Society, 14(2): 97-106.

Kuhn, T.S. (1970) The Structure of Scientific Revolutions, 2nd edn. Chicago, IL: University of Chicago Press. 
Latour, B. (1988) Wetenschap in actie - Wetenschappers en technici in de maatschappij. Amsterdam: Bert Bakker.

MacKenzy, D. and J. Wajcman (1985) The Social Shaping of Technology: How the Refrigerator Got its Hum. Milton Keynes: Open University Press.

Miller, D. (1987) Mass Consumption and Material Culture. Oxford: Basic Blackwell.

Mosco, V. (1990) 'Computers and Democracy', in J. Berleur, A. Clement, R. Sizer and D. Whitehouse (eds) The Information Society: Evolving Landscapes, pp. 215-31. New York and North York, Ontario: Springer-Verlag and Captus Press.

Mosco, V. (1996) 'Myth-ing Links: Power and Community on the Information Highway', The Information Society 14(1): 57-62.

Nelson, R. and S. Winter (1977) 'In Search of a Useful Theory of Innovation', Research Policy 6: 36-76.

Rip, A., T.J. Misa and J. Schot (eds) (1995) Managing Technology in Society: The Approach of Constructive Technology Assessment. London: Pinter.

Rogers, E. (1983) Diffusion of Innovations. New York: Free Press.

Rommes, E., E. Van Oost and N. Oudshoorn (forthcoming) 'Gender in the Design of the Digital City'.

Schalken, C.A. and J. Flint (1995) Handboek Digitale Steden. Amsterdam: De Digitale Stad.

Schalken, C.A. and P.W. Tops (1994) 'De Digitale Stad - Een onderzoek naar de achtergrond en meningen van haar inwoners', in V. Bekkers (ed.) Wegwijs op de digitale snelweg, pp. 41-60. Amsterdam: Otto Cramwinckel Uitgever.

Schalken, C.A., P.F. Depla and P.W. Tops (1996) 'Technology and the Modernization of Local Democracy', in V. Bekkers, B.-J. Koops and S. Nouwt (eds) Emerging Electronic Highways: New Challenges for Politics and Law, pp. 35-46. The Hague: Kluwer Law International.

Schön, D.A. (1993) 'Generative Metaphor: A Perspective on Problem-setting in Social Policy', in A. Orthony (ed.) Metaphor and Thought, pp. 137-63. Cambridge: Cambridge University Press.

Silverstone, R., E. Hirsch and D. Morley (1991) 'Information and Communication Technologies and the Moral Economy of the Household', in K. Sorensen and A.-J. Berg (eds) Technology and Everyday Life: Trajectories and Transformations, pp. 13-46. Oslo: Norwegian Research Council for Science and the Humanities.

Sorensen, K. (1996) 'Learning Technology, Constructing Culture: Socio-technical Change as Social Learning', STS-working paper no. 18/96, Centre for Technology and Society, Trondheim.

Van Bastelaer, B. and C. Lobet-Maris (eds) (1999) Social Learning regarding Multimedia Developments at a Local Level: The Case of Digital Cities. Namur: CITA - University of Namur.

Van Dijk, J. (1997) 'The Reality of Virtual Communities', Trends In Communication 1(1): 39-63.

Van Lieshout, M. (1999) 'The Digital City of Amsterdam: Between Public Domain and Private Enterprise', in B. van Bastelaer and C. Lobet-Maris (eds) Social Learning regarding Multimedia Developments at a Local Level: The Case of Digital Cities. Namur: CITA-University of Namur.

Van Lieshout, M., T.E. Egyedi and W.B. Bijker (in press) Social Learning in Educational Multimedia. Ashcroft: Ashgate Publications.

Van Twist, M. (1995) Verbale vernieuwing: Aantekeningen over de kunst van de bestuurskunde. Amsterdam: VUGA. 
Williams, R., R. Slack and J. Stewart (2000) Social Learning in Multimedia - Final Report. Edinburgh: Research Centre for Social Sciences.

Wynne, B. (1995) 'Technology Assessment and Reflexive Social Learning: Observations from the Risk Field', in A. Rip, T.J. Misa and J. Schot (eds) Managing Technology in

Society: The Approach of Constructive Technology Assessment, pp. 19-36. London: Pinter. Woolgar, S. (1991) 'Configuring the User: The Case of Usability Trials', in J. Law (ed.) A Sociology of Monsters: Essays on Power, Technology and Domination, pp. 58-99.

London: Routledge.

M.J. VAN LIESHOUT is currently working as senior researcher at the Institute of Strategy, Technology and Policy, at the Dutch Organization of Applied Science (TNO-STB). He was previously employed at the University of Maastricht, as a member of the international research consortium that conducted the European SLIM study (Social Learning in Multimedia). This article is one of the results of his contribution to that research project. He has worked for a number of years at the University of Nijmegen, lecturing on societal aspects of Informatics, and has been engaged with the Dutch Rathenau Institute, organizing societal debates and research on topics such as the electronic highway and elderly people.

Address: TNO-STB, PO 6030, 2600 JA Delft, The Netherlands. [email: vanlieshout stb.tno.nl] 